\title{
Effect of fabric biaxial prestress on the fatigue of woven E-glass/polyester composites
}

\begin{abstract}
In this study, woven E-glass/polyester composites are prepared with different equi-biaxially fabric prestressing levels. Fatigue tests were carried out to assess the effect of fabric pretension on the life of the prestressed composite under cyclic loading. The proposed prestressing method was implemented by applying an identical tension load to the warp and fill bundles and maintaining it until the matrix has cured. The monotonic quasi-static tensile tests were first conducted on the specimens with fabric prestressing level up to $100 \mathrm{MPa}$ to estimate the optimum level of fabric prestressing. Tensionï tension fatigue tests were then conducted to the samples with three different cases of prestressing, such as non-prestressed (pristine), prestressed at $50 \mathrm{MPa}$ (optimum) and prestressed at $100 \mathrm{MPa}$ (over-prestressed). For the composite system used throughout this work, the fatigue life of the samples prestressed at the optimum level was extended up to $~ 43 \%$. The Sï Nf relationships showed that the fabric prestressing method could be used to extend the fatigue life of composites in the intermediate and low-stress regions. The improvement in fatigue life due to fabric prestressing could decrease with increasing the off-axis fabric orientation. Fabric prestressing method was not recommended when the normalized peak stress is higher than $\sim 0.6$.
\end{abstract}

Keyword: Equi-biaxially prestressing; Composite fatigue life; Residual stress; Prestressing level; Plain-weave fabric orientation 